\title{
Understanding the consequences of diversification on financial stability
}

\author{
Opeoluwa Banwo ${ }^{(D)}$ - Paul Harrald ${ }^{2}$. \\ Francesca Medda ${ }^{1}$
}

Received: 11 May 2017 / Accepted: 25 February 2018 / Published online: 6 March 2018 (C) The Author(s) 2018. This article is an open access publication

\begin{abstract}
In this paper, we study the consequences of diversification on financial stability and social welfare using an agent based model that couples the real economy and a financial system. We validate the model against its ability to reproduce several stylized facts reported in real economies. We find that the risk of an isolated bank failure (i.e. idiosyncratic risk) is decreasing with diversification. In contrast, the probability of joint failures (i.e. systemic risk) is increasing with diversification which results in more downturns in the real sector. Additionally, we find that the system displays a "robust yet fragile" behaviour particularly for low diversification. Moreover, we study the impact of introducing preferential attachment into the lending relationships between banks and firms. Finally, we show that a regulatory policy that promotes bank-firm credit transactions that reduce similarity between banks can improve financial stability whilst permitting diversification.
\end{abstract}

Keywords Contagion - Diversification $\cdot$ Systemic risk · Agent based models

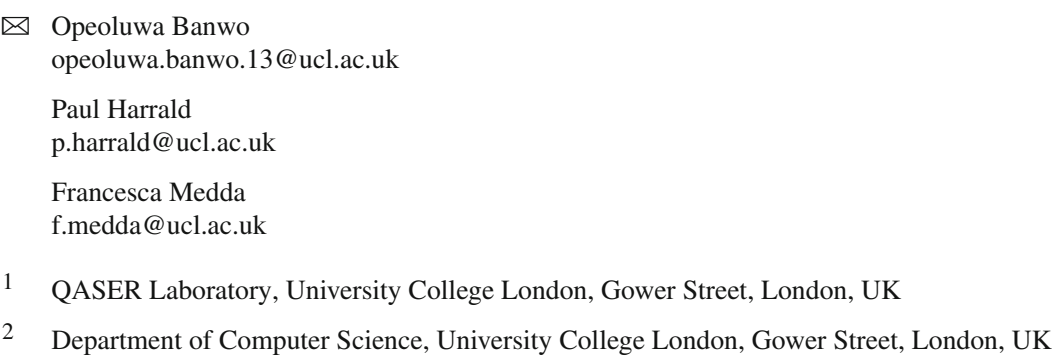




\section{Introduction}

There is growing similarity in the asset side of banks' balance sheets due to increased participation in the same global markets (Cai et al. 2012; Liu 2015; Wagner 2010). We consider the consequences of this on financial stability. A major motivation for the increasing similarity is rooted in the standard financial and perhaps intuitive diversification advice "Don't put all your eggs in one basket". In fact, the seminal work of Markowitz (1952) on portfolio selection provides evidence that diversification across various asset classes reduces the aggregate risk of a bank's portfolio. It is thus reasonable to conclude that if each bank becomes less risky due to diversification then the financial system should become more stable. Moreover, several reports before the 2007 financial crisis found little evidence for a systemic breakdown of the financial system owing to the high diversification levels at individual banks due to the extent of financial innovation (Bartram et al. 2007; Elsinger et al. 2006; Furfine 2003). However, the financial system still came close to near collapse even though banks, especially the big ones, had become largely diversified.

This conundrum stems from an individual bank not considering the fact that other banks are pursuing the same risk objective by diversifying their balance sheets across the same set of asset classes. This results in individual banks becoming less differentiable. From a systemic perspective, a less differentiable set of banks increases fragility and exacerbates the risk of joint failures of a large part of the financial system, which can have serious consequences on social welfare. This phenomenon draws a parallel in ecological studies where genetic diversity, for instance, is shown to result in greater resilience to disease spread (see Tilman 1999, for a detailed discussion).

Thus, diversification appears to serve multiple roles; on one hand, it makes banks less risky but on the other hand it increases the risk of joint failures. This dual role of diversification on financial stability has prompted active discussions amongst policy makers and academics in a growing number of studies. For instance, the reports by Allen and Carletti (2006), Allen and Gale (2005), Wagner (2008, 2010), Wagner and Marsh (2006) show that diversification increases the likelihood of a systemic crisis due to the homogenization of the financial system even though it is desirable in terms of reducing the probability of an individual bank failure. Similar findings are reported by Battiston et al. (2012). In a related work, Caccioli et al. (2014) study the role of diversification on financial contagion due to overlapping portfolios and showed that the system undergoes two phase transitions with increasing diversification between which global cascades can occur. This finding is also reported in the work by Raffestin (2014). Tasca et al. (2014) show that diversification can have ambiguous consequences on the stability of the financial system by studying the joint impact of leverage and diversification on financial stability using a structural risk model based on the framework proposed by Merton (1974). They show that a critical leverage value can result in alternating phases of stability and instability depending on the diversification strategy. Finally, while our focus is on diversification, however our work is also related to the literature on bank herding since they both lead to concentrations in the same set of activities (see, for instance, Acharya and Yorulmazer 2005, 2007).

We contribute to this strand of literature by studying the consequences of diversification on the stability of the financial system in terms of idiosyncratic and systemic 
risk endogenously produced from an evolving stylised economy, which sets our work apart from previous studies. Moreover, our approach provides a simple mechanism for analysing the full effect of regulatory responses to negative externalities associated with the impact of diversification on financial stability and the wider economy.

Our approach consists of a deliberately simplified agent based model that couples a financial system and the real economy. There is a large literature on macro-finance interaction models including Bask (2012), De Grauwe and Macchiarelli (2015), Lengnick and Wohltmann (2016), Naimzada and Pireddu (2014), Westerhoff (2012). These works couple agent-based financial(stock) market and mainstream macro models. However, we deviate from these models by focusing on externalities resulting from credit/loan network rather than traded equities/shares. ${ }^{1}$ In a nutshell, the model implements a self-organising economy populated by rationally bounded heterogeneous agents including firms, households and banks interacting within different markets without central coordination (see Fagiolo and Roventini 2012 for an elaborate discussion on decentralised economic systems). The model dynamics leads to the emergence of bank-bank and bank-firm links that are strategically formed and terminated. These networks serve as channels of contagion and shock propagation. In this sense, the model shares some similarity with the strand of literature on multilayer network theory and financial contagion (Caccioli et al. 2015; Montagna and Kok 2016; Lux 2016; Martinez-Jaramillo et al. 2014; Poledna et al. 2015) since it leads to the formation of different network structures that serve as contagion reinforcing mechanisms.

The rest of this paper is organised as follows. In Sect. 2, we describe the main features of the model. Section 3 characterises the stability features of the financial system due to diversification. We then propose a regulatory policy that permits diversification without exacerbating systemic risk in Sect. 4. Finally, a summary of our findings is presented in Sect. 5 .

\section{Model}

For the purpose of this study, we extend the CRISIS Mark 1 agent based model extensively studied in Delli Gatti et al. (2011), Gualdi et al. (2015), Klimek et al. (2015), Poledna and Thurner (2016). The original CRISIS Mark 1 model specifies a closed system that couples the real economy and a limited financial system. A closed system in this sense implies that all money stay within the economy and is held by the agents. We extend the model to include different production sectors in the real economy. Furthermore, we include simplified credit and interbank markets so that banks play an active role in the economy unlike the original model specification in which the banking sector is passive.

Figure 1 provides a high-level view of the agents and their interactions within the model discussed elaborately in the following sections:

\footnotetext{
1 This is motivated by the fact that empirical reports published in 2007 for banks in the United Kingdom, for instance, suggest that on average $80 \%$ of a bank's balance sheet represented loans given to firms while only about $10 \%$ was allocated to equities (see Anand et al. 2013).
} 


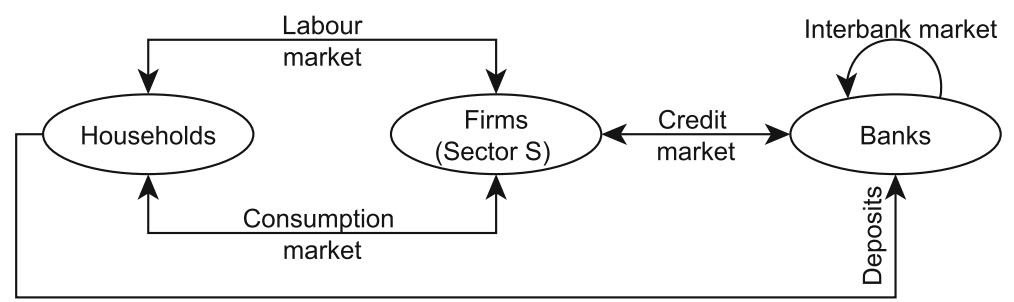

Fig. 1 High-level view of agents' interactions

In a nutshell, the model implements a self-organising economy populated by rationally bounded heterogeneous agents namely firms, households and banks interacting within different markets without central coordination. Households interact with firms on the labour and consumption market, banks interact with other banks on the interbank market while firms and banks interact within different sectors on the credit market resulting in a constantly evolving (i.e. links are strategically formed and terminated) bank-bank network and bipartite network of bank-firm links respectively.

We validate the model in terms of its ability to reproduce phenomenological laws observed in real economies namely Okun (Prachowny 1993) and Beveridge curves (Nickell et al. 1960). Moreover, we observe the emergence of alternation of booms and recessions in aggregate output and Zipf distribution of firm sizes (Axtell 2001). See "Appendix A" for an elaborate discussion on the model calibration and validation.

The economy we consider comprises different sectors and each firm is assigned to a sector. We exogenously control the level of diversification (diversity) of the financial system using a single parameter that fixes the number of sectors each bank can lend to on the credit market. The goal of this paper is to understand the role of diversification on financial stability. As such, we abstract from strategic processes used by banks in choosing a particular portfolio structure as in Wagner (2011), who show that investors are motivated towards heterogeneous portfolio configurations due to the risk of joint liquidation.

Our model belongs to the class of "one-step" models (see Delli Gatti et al. 2011; Dosi et al. 2010; Klimek et al. 2015 for examples). In contrast, other works in the literature (Erlingsson et al. 2013; Gaffeo et al. 2008; Lengnick 2013) use models that capture heterogeneous and real-world timescales. In our model, agents carry out the following sequence of operations or decisions in each time period.

1. Firms set their production and pricing strategies heterogeneously

2. Firms update their labour and loan demand accordingly.

3. Banks propose interest rates to firms heterogeneously and may raise liquidity to service loans.

4. Firms recruit (fire), produce goods and pay wages

5. Banks receive deposits from their customers

6. Households attempt to spend a proportion of their savings on consumption.

7. Banks and firms attempt to meet obligatory payments namely dividends, loan repayments and interests.

8. Illiquid firms are liquidated, and their assets shared pro-rata among creditors 
9. Banks with negative equity are said to be insolvent and are bailed-in by their creditors and(or) customers

\subsection{Firms}

1. There are $N_{f}$ firms in the model. Each firm is randomly assigned to a sector $s$ and produces perishable goods. ${ }^{2}$ The goods produced by firms are perfect substitutes for the consumer. There are $N_{s}$ sectors in the model.

2. A sector in our model represents a conceptual group of random firms. A firm follows heuristic rules proposed in Delli Gatti et al. (2011), Gualdi et al. (2015) and Klimek et al. (2015) in setting its production and price targets. The rules are based on the demand for a firm's goods and average market price in its sector. In a nut shell, Eq. 1 implies that if demand is lower than expected a firm will reduce its production target provided its price is less than the average price in its sector otherwise it reduces its price instead. The reverse is followed if the firm sold all its goods in the previous time step.

$$
\begin{aligned}
& Y_{i}^{T}(t+1)=Y_{i}(t)\left[1+\gamma_{y} \Gamma_{i}(t)\right] \text { if }\left\{\begin{array}{l}
Y_{i}(t)=D_{i}(t) \text { and } \\
p_{i}(t)>\bar{p}_{s}(t)
\end{array}\right] \\
& Y_{i}^{T}(t+1)=Y_{i}(t)\left[1-\gamma_{y} \Gamma_{i}(t)\right] \text { if }\left\{\begin{array}{l}
Y_{i}(t)>D_{i}(t) \text { and } \\
p_{i}(t)<\bar{p}_{s}(t)
\end{array}\right. \\
& p_{i}(t+1)=p_{i}(t)\left[1+\gamma_{p} \Gamma_{i}(t)\right] \text { if }\left\{\begin{array}{l}
Y_{i}(t)=D_{i}(t) \text { and } \\
p_{i}(t)<\bar{p}_{s}(t)
\end{array}\right. \\
& p_{i}(t+1)=p_{i}(t)\left[1-\gamma_{p} \Gamma_{i}(t)\right] \text { if }\left\{\begin{array}{l}
Y_{i}(t)>D_{i}(t) \text { and } \\
p_{i}(t)>\bar{p}_{s}(t)
\end{array}\right.
\end{aligned}
$$

where $D_{i}(t)$ is the total demand for the goods produced by firm $i$ at time $t$, and

$$
\bar{p}_{s}(t)=\frac{\sum_{i}^{s} p_{i}(t) D_{i}(t)}{\sum_{i} D_{i}(t)}
$$

$\bar{p}_{s}(t)$ is the average price of sold goods in sector $s$ at time $t, \Gamma_{i}(t)$ is drawn from the uniform distribution $U[0,1]$ for each firm while $\gamma_{y} \& \gamma_{p}$ drawn from $U[0,1]$ represent the production and price adjustment parameter respectively. $Y_{i}^{T}$ $\& Y_{i}$ denote the target and realised production of firm $i$. We assume that the case $Y(t)=D(t)$ also implies the case $Y(t)>D(t)$ in our implementation.

3. Each firm computes the required workforce to achieve its target $Y_{i}^{T}$ based on the following production function.

$$
Y_{i}^{T}(t)=\alpha L_{i}^{d}(t)
$$

\footnotetext{
2 Perishable in this context means the unsold goods cannot be preserved for the next time period.
} 
Fig. 2 A stylised representation of a typical bank's balance sheet structure

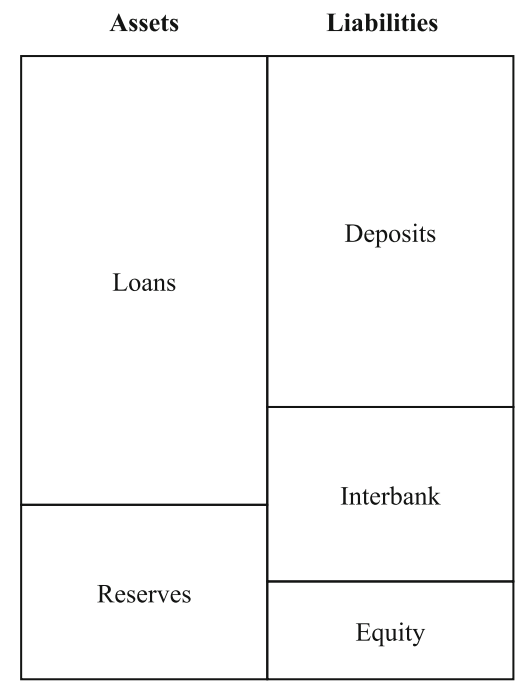

where $L_{i}^{d}(t)$ denotes the labour demand for firm $i$ at time $t$

4. Each firm randomly approaches one of the registered banks in its sector for loans to cover its liquidity shortfall given by:

$$
\max \left(0, L_{i}^{d}(t) W_{i}(t)-C_{i}\right)
$$

where $C_{i}$ denotes the cash of firm $i$ and $W_{i}$ represents its wage.

5. As in Klimek et al. (2015), Poledna and Thurner (2016), banks propose interest rates for each firm using an increasing function of the firm's financial fragility $\mathcal{L}_{i}$ defined as the ratio of its total debt to its cash i.e.

$$
r_{b, i}(t)=r_{0}(1+\epsilon)\left[1+\tanh \left(\mu \mathcal{L}_{i}(t)\right)\right]
$$

where $r_{0}$ is the baseline interest rate, $\epsilon$ is drawn from the uniform distribution $U[0,1]$ to capture bank variations such as investment strategy and $\mu$ is a constant that controls the sensitive of the process. We do not model a central bank that would typically set $r_{0}$ in response to changing economic conditions. Rather, we assume that $r_{0}$ is fixed to ensure consistency across the various simulations described in this work.

6. Each firm attempts to repay a percentage $\tau$ and the interest due on its loan. Also, if the firm makes a profit after meeting these financial obligations, it pays a certain percentage $\eta$ of this profit to its owner.

\subsection{Banks}

1. There are $N_{b}$ banks in the model. We consider a simplified structure for a typical bank's balance sheet as shown in Fig. 2. 


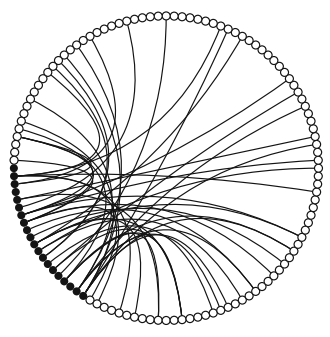

(a)

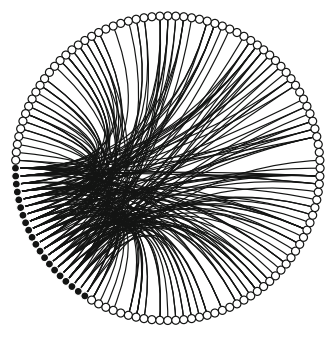

(b)

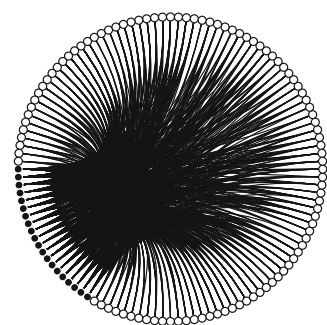

(c)

Fig. 3 Bank-firm network for different values of $\phi_{s}$. Black circles: banks. White circles: firms. a $\phi_{s}=1$, b $\phi_{s}=10, \mathbf{c} \phi_{s}=20$

2. A bank receives deposits from its customers. We assume that banks only receive deposits from households (including firm owners) but not from firms in-order to keep the model simple.

3. A bank can only provide loans to $\phi_{s}$ distinct sectors. We consider $\phi_{s}$ as a bank's diversification level and not its number of lending links with firms (i.e. its degree). This approach implies that we can exogenously tune the level of diversification of banks using a single parameter such that $1 \leq \phi_{s} \leq N_{s}$. As such, banks become exposed to the same firms with increasing $\phi_{s}$ as shown in Fig. 3. Specifically, we show the bank-firm networks for different values of $\phi_{s}$ in Fig. 3.

4. We set $N_{s}=N_{b}$ in-order to create the case where all banks lend to all sectors and where all banks lend to distinct sectors.

5. A bank supplies the loan requested by firms. If the bank does not have enough cash to fulfil the due loan, it attempts to raise the shortfall from $M_{b}$ other banks on the interbank market. If it is unable to raise the required cash, it resorts to the lender of last resort. ${ }^{3}$

6. Each bank services the interest due on its interbank debt and repays a proportion $\tau$ of this debt. Our focus is on bank failures due to balance-sheet insolvency; thus, we abstract away from illiquidity by assuming that an illiquid bank that cannot raise cash from the interbank market can always resort to the central bank to cover its liquidity shortfall.

7. A bank is required to keep a percentage $\zeta$ of its total deposits in a reserve account at the central bank.

\subsection{Households}

As in Delli Gatti et al. (2011), Gualdi et al. (2015) and Klimek et al. (2015), households in our model are endowed with the following behaviours:

\footnotetext{
3 This approach implies that banks can always raise enough cash to provide loans. While this assumption is rather simplified, it allows us to focus solely on the macroeconomic impact of diversification without mixing in cash constraint. We have also experimented with another version in which banks cannot raise cash from the central bank to provide loans and find that the qualitative features of the model are preserved.
} 
1. Each household is either a firm owner or a worker. A firm owner does not work but receives dividend payments each time period depending on whether or not its firm makes a profit. A worker supplies one unit of labour inelastically.

2. Each household is randomly assigned to a bank and continues to save its cash in this bank throughout the simulation.

3. At every time step, an employed household switches to a firm offering higher wages with probability $\varphi$. Unemployed workers are then randomly assigned to firms with vacancies.

4. Each household attempts to spend a proportion $C_{h}$ of its savings in $M_{f}$ randomly chosen firms. The selected firms are then approached in increasing order of their selling prices. Also, it is possible that a household's needs are not completely satisfied thus making the consumption market inefficient.

\subsection{Contagion mechanism}

The consumption market dynamic described above induces random shocks in the performance of firms. In the event that a firm is unable to meets its financial obligations, its owner would try to cover the liquidity shortfall. In-case this is not sufficient, the firm is liquidated and its asset plus the owner's wealth is shared pro-rata among its creditors. The owner immediately starts a new firm with expected demand and price set to the average across all firms. This process may result in some of its creditors (i.e. banks) writing-off portions of the loans. This dynamic may cause one or more banks to fail.

A bank is deemed to have failed whenever its equity falls below zero (i.e. it becomes insolvent) due to loan defaults. A failed bank is resolved using a bail-in resolution tool (see Benczur et al. 2017; Conlon and Cotter 2014; Hüser et al. 2017; Klimek et al. 2015 for elaborate discussions on bail-in). Basically, this involves restructuring the balance sheet of the failed bank such that some of its liabilities (interbank loans \& deposits) are converted into equity.

We implement this by subtracting a one-time levy (required to cover the negative equity position) and a small overhead $\xi$ (required to ensure continued bank operations) from its deposit and interbank loan accounts proportional to their sizes. Hence, the losses are borne by the bank customers and other banks that have provided loan to it on the interbank market in exchange for ownership rights. This procedure effectively creates a contagion channel through the bank-bank network and enables some of the bankruptcy cost to be borne directly by households.

\section{Stability analysis}

In this section, we investigate the systemic and idiosyncratic risk inherent in the financial system based due to only the bank-firm network. Idiosyncratic risk refers to the probability of a one-off or isolated bank failure. The failure of Barings bank in 1995, for instance, was an isolated event and specific to Barings (see Fay 1997 for an elaborate discussion on this event). Systemic risk on the other hand refers to the probability of a large part of the financial system failing. A good example is the 2007 financial 
Fig. 4 Emergent idiosyncratic risk as a function of $\phi_{s}$ due to only loan defaults using 300 simulations with each simulation spanning 2500 time periods

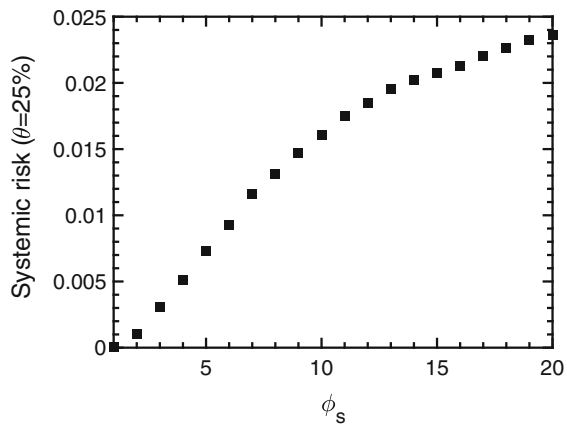

(a)
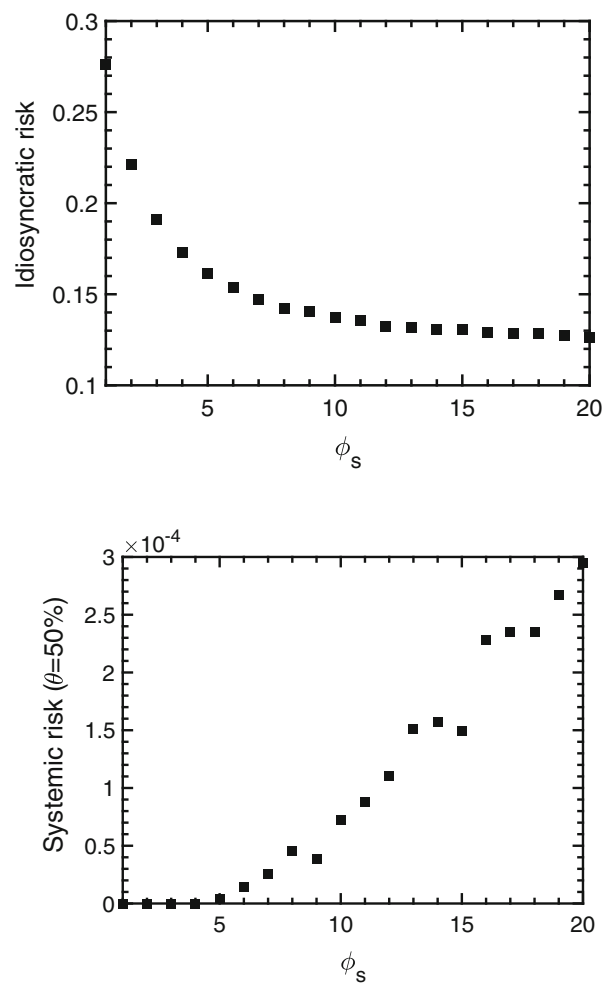

(b)

Fig. 5 Emergent systemic risk as a function of $\phi_{s}$. Diversification increases systemic risk. Results remain qualitatively unchanged with respect to $\theta$. $\mathbf{a} \theta=25 \%, \mathbf{b} \theta=50 \%$

crisis during which major financial institutions like American International Group (AIG), Bear Stearns, Lehman Brothers, Citigroup etc. either failed or had to be saved from failing by different government intervention schemes (Bullard et al. 2009).

We measure systemic risk in terms of the probability of observing a global cascade of bank defaults (i.e. joint bank failures) while idiosyncratic risk refers to the probability of observing an isolated bank default in a simulation. In our analysis, a global cascade of defaults is said to occur if the number of bank failures exceeds a defined threshold $\theta$. Unless otherwise stated, we define $\theta$ as $25 \%$ of the total number of banks and abstract from the impact of the bank-bank network by counting only bank failures before bailin occurs in each time period. Moreover, we account for randomness present in the labour, consumption and credit market by averaging over 300 simulations with each simulation spanning 2500 time periods.

Figure 4 reveals that idiosyncratic risk is decreasing with diversification. In contrast, Fig. 5a shows that systemic risk is increasing with diversification. We find that the qualitative behaviour of this result is preserved by changing $\theta$ to $50 \%$ as shown in Fig. 5b. The reason why increasing diversification appears to increase systemic risk but reduce idiosyncratic risk can be intuitively understood from the fact that banks 
Fig. 6 Emergent systemic risk as a function of $\phi_{s}$. Squares: bank-firm network only. Circles: joint impact of the bank-firm and bank-bank network

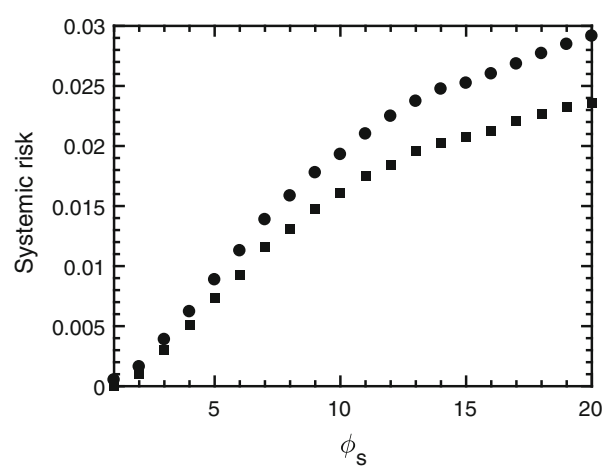

become less diverse and increasingly exposed to the same sectors as they become more diversified (i.e. the bank-firm network becomes more connected) such that negative spill overs emanating from the real sector during a recession is able to affect many banks. However, diversification ensures that a bank's risk is not concentrated in any one sector such that the negative impact of downturns in a sector becomes smaller on the bank, effectively reducing the probability of the bank failing.

\subsection{Impact of contagion}

In the discussion above, we abstracted from the impact of contagion arising from the bank-bank network (i.e. links between banks) and concentrated only on the impact of the bank-firm network. In this section, we briefly characterise the joint impact of both network layers. The squares in Fig. 6 denote systemic risk due to only the bankfirm network while the circles show the joint impact of the bank-firm and bank-bank networks. Thereby suggesting that the bank-bank network serves to amplify contagion in agreement with reports in Caccioli et al. (2015), Lux (2016) and Wagner (2010).

Specifically, it appears the contagion impact of the bank-bank network becomes pronounced with increasing diversification. In contrast to natural expectations that diversification should reduce contagion spread from bank failures since it makes the banks individually safer. This follows from the fact that the negative spill over from the real economy would initially weaken more banks as they become more exposed to the same sectors such that additional losses suffered through the bank-bank network may easily trigger more cascading defaults.

\subsection{Social cost}

We measure social cost in terms of the average rate of losses from the financial system since this is the amount in Dollars that would be required if the banks were to be bailed out by the government with taxpayers' money. We define average rate of losses over a period $T$ as $A_{L}=\overline{\sum_{t=1}^{T}}$ TotalSystemLiabilities TotalSystemAssets $_{t}$ and plot it as a function of $\phi_{s}$ in the left panel of Fig. 7 . 


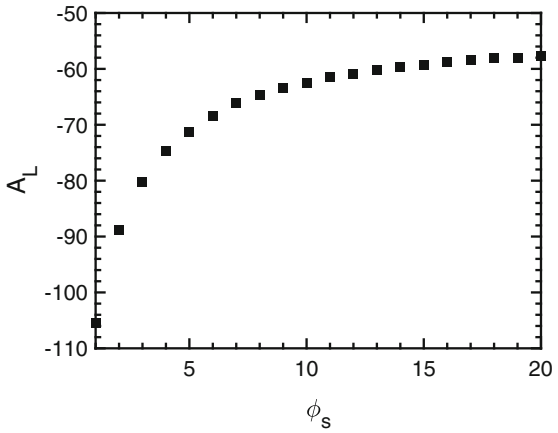

(a)

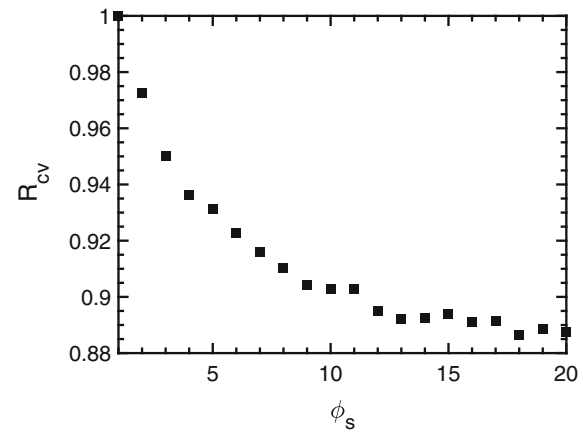

(b)

Fig. 7 Average rate of losses and credit volume as a function of $\phi_{s}$. a Average rate of losses, $\mathbf{b}$ relative credit volume

Our notation implies that increasing values denote greater loss. As such Fig. 7 suggests that increasing diversification leads to higher social cost. Moreover, in the right panel of Fig. 7, we show the impact of diversification on the real economy in terms of the aggregate credit volume. Specifically, we compare each level of diversification relative to the completely un-diversified case (i.e. $\phi_{s}=1$ ). The plots suggest that diversification is having a negative impact on the real economy. This follows from the fact that diversification leads to a higher risk of the joint failure of many banks.

\subsection{Robust yet fragile}

The financial system has been shown to exhibit a "robust-yet-fragile" behaviour such that while the likelihood of a global cascade is low, the effects are usually widespread whenever it occurs (Caccioli et al. 2014; Gai and Kapadia 2010; Mistrulli 2011). We contribute to this strand of studies by investigating if our model also produces the "robust-yet-fragile" property? We do this by computing the conditional extent of cascades which we define as the average number of bank failures for the cases when global cascades occur.

In Fig. 8, we plot the probability of a global cascade and the corresponding extent of cascades as a function of $\phi_{s}$. We find that while global cascades are very unlikely, however, a large part of the financial system is hit whenever it occurs particularly for low levels of diversification. For instance, while the probability for a global cascade is almost negligible (i.e. $5.2267 \times 10^{-4}$ ) when $\phi_{s}=1$, however, more than $25 \%$ of banks are hit whenever a global cascade does occur.

\subsection{Preferential bank-firm model}

So far, we have characterised the stability of the system based on the bank-firm link formation process outlined in Sect. 2.1. However, the work done by de Masi and Gallegati (2012), Marotta et al. (2015) suggests the presence of preferential lending 
Fig. 8 Probability and extent of global cascades as a function of $\phi_{s}$. Squares: probability for global cascades. Circles: conditional extent of cascades

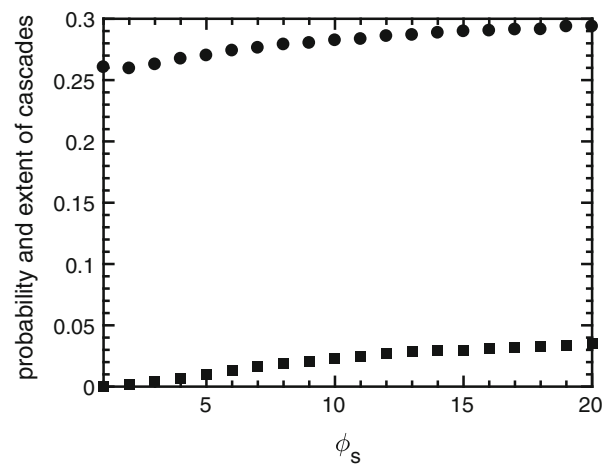

relationships between banks and firms. In particular, they show that the degree distribution of banks in the bank-firm network is dependent on their balance sheet sizes such that the big banks tend to have more links with the real sector than small banks.

Moreover, empirical studies suggest that firms tend to form persistent links with certain banks in order to minimise agency cost and develop readily accessible credit lines (Agarwal and Ann Elston 2001; Ferri and Messori 2000; Fidrmuc et al. 2015). It then becomes interesting to ask what is the stability impact of introducing this kind of preference structure into the network of loans from banks to firms? To address this question, we re-design the bank-firm lending relationship such that a firm in a sector $s$ forms a lending relationship with bank $b$ from the set $B_{s}$ of banks registered in sector $s$ with a probability $p_{b f}$. We compute $p_{b f}$ as a function of the bank's balance sheet size $A_{b}$ and the number of existing links between $f$ and $b\left(\mu_{b f}\right)$ i.e.

$$
p_{b f}=\frac{A_{b} \mu_{b f}}{\sum_{b \in B_{s}} A_{b} \mu_{b f}}
$$

This network formation process typically introduces a scale-free structure through the creation of a few banks with relatively higher degrees (i.e. more exposures to the real sector) than others. In Figs. 9 and 10, we compare the stability impact of this structure to our benchmark model using the same initial configuration and random number seed for respective simulations. We refer to the original bank-firm model outlined in Sect. 2.1 as the benchmark model.

We find that the emergent risk profiles retain the same features identified in the benchmark case (i.e. lower idiosyncratic risk and higher systemic risk with increasing diversification). However, the plot in Fig. 9 suggests that preferential attachment induces more idiosyncratic risk into the system, especially for high levels of diversification. This follows from the fact that the preferential network formation process we consider results in some banks that are over-diversified (thus less likely to fail) and others that are under-diversified and more prone to default. This effectively increases the aggregate idiosyncratic risk in the financial system relative to the case of the benchmark model.

Furthermore, the plot in Fig. 10 suggests that preferential attachment reduces systemic risk. This provides more credence to reports in the complex networks literature 
Fig. 9 Emergent idiosyncratic risk as a function of $\phi_{S}$. Squares: benchmark model. Circles: preferential model

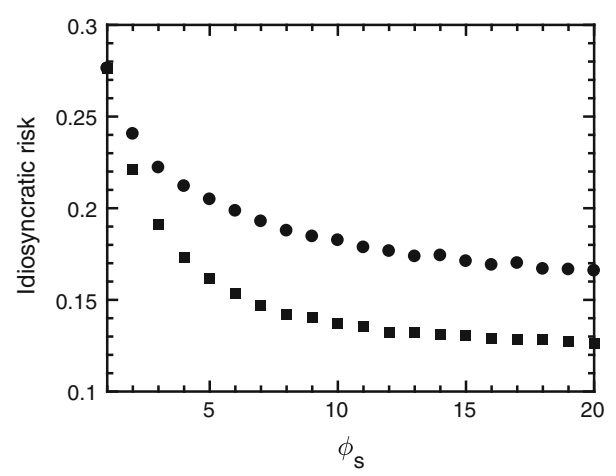

Fig. 10 Emergent systemic risk as a function of $\phi_{s}$. Squares: benchmark model. Circles: preferential model

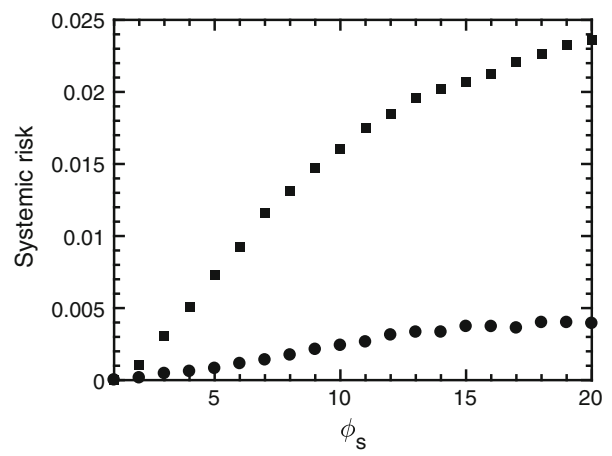

that show that scale-free networks comprising few highly connected nodes (i.e. hubs) and many nodes with low connectivity are more robust to random shocks (Albert et al. 2000, 2002; Caccioli et al. 2011; Gai et al. 2011). The stability analysis from the benchmark simulation which shows that diversification reduces idiosyncratic risk while diversity decreases systemic risk provides an intuition for this result. Basically, the evolving preferential network effectively introduces more diversity into the system through the creation of many relatively isolated banks (i.e. banks with low degrees), which is desirable from the point of view of reducing the probability of joint failures (i.e. systemic risk).

\section{Policy impact analysis}

In the previous section, we showed that diversification reduces idiosyncratic risk, however, it also makes the financial system less diverse consequently leading to more joint failures (i.e. higher systemic risk). It then becomes interesting to ask if it is possible to design polices that permit diversification without exacerbating systemic risk?

A possible way of achieving this is to increase capital requirements of banks relative to their similarity with the rest of the financial system such that banks with higher degrees of similarity are required to more capital. Moreover, it is known from the literature that higher capital requirements improves the stability of the financial system. 
However, higher capital requirements come at a cost of reduced lending to the real sector (see Bridges et al. 2014; Brooke et al. 2015). As such, we investigate the possibility of an alternative regulatory policy that achieves the same objective without requiring banks to hold additional capital.

The policy we consider is motivated by the fact that a bank does not internalise the impact of its activities on the build-up of systemic risk in the financial system (Acharya 2009; Wagner 2010). We model this policy by defining a similarity measure $S_{b}$ for bank $b$ relative to the rest of the financial system as:

$$
S_{b}=\sum_{a \in B_{b}} \frac{|F(b) \cap F(a)|}{\max (|F(b)|,|F(a)|, 1)}
$$

Where $B_{b}$ is the set of banks registered in the same sector(s) as bank $b$ and $F(x)$ gives the set of firms with lending relationship(s) with bank $x$. We have included the constant 1 into Eq. 7 to avoid division by zero. We further define $\Delta S_{b f}$ as the additional increase in the similarity for a bank $b$ conditional on a credit transaction with a firm $f$. Finally, we implement a simple framework such that firms are more likely to transact with banks having lower $\Delta S_{b f}$. Thus, deviating from the random bank-firm link formation process outlined in Sect. 2.1. The framework is such that given $\Delta S_{b f}$ a firm $f$ transacts with bank $b$ with probability $\omega_{b f}$ defined as:

$$
\begin{array}{r}
\omega_{b f}=\frac{1 / \Delta S_{b f}}{\sum_{a \in B_{b}} 1 / \Delta S_{b f}} \\
\Delta S_{b f}=S_{b f}-S_{b}
\end{array}
$$

Following the intuition developed in Eq. 7, we define $S_{b f}$ as: ${ }^{4}$

$$
S_{b f}=\sum_{a \in B_{b}} \frac{|(F(b) \cup f) \cap F(a)|}{\max (|(F(b) \cup f)|,|F(a)|, 1)}
$$

A possible way of implementing this policy is for a central bank to compute $\Delta S_{b f}$ and translate this into a tax that reduces lending activities of banks with high $\Delta S_{b f}$. This could be in the form of a model that essentially increases the lending rates from such banks, which would ultimately incentive firms to transact with those banks with low $\Delta S_{b f}$. Poledna and Thurner (2016), for instance, adopt a similar structure where the interest rate proposed by a bank is proportional to its "debtrank". However, we do not model this translation since our interest lies in understanding the effectiveness of the policy rather than its implementation details.

We compare the stability impact of this policy relative to our benchmark model using the same initial configuration and random number seed for respective simulations. The plots in Fig. 11 show that the policy is effective at reducing systemic risk whilst keeping the benefit of diversification of reducing idiosyncratic risk. This follows from the fact that the policy induces a self-arranging network topology between banks and firms

\footnotetext{
${ }^{4}$ Equation 9 implies that $S_{b f} \geq S_{f}$. In the case that $\Delta S_{b f}=0$, we add a small number to prevent division by zero in Eq. 8 .
} 

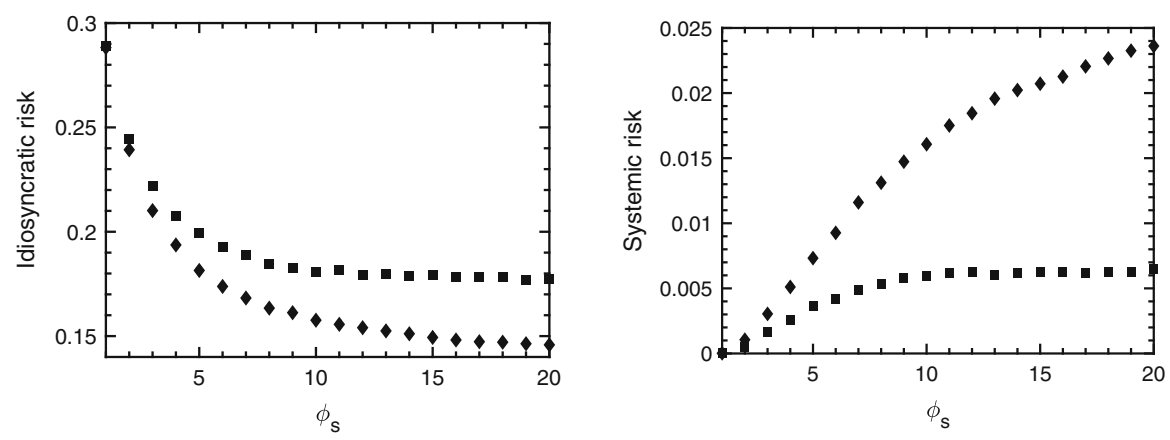

Fig. 11 Idiosyncratic and systemic risk as a function of $\phi_{S}$. Diamonds: Without policy. Squares: With policy. Results refer to 300 simulations with each simulation spanning 2500 time periods

that promotes dissimilarity in the financial system even with increasing diversification which ultimately reduces the build-up of systemic risk. Although, idiosyncratic risk is relatively higher with our policy however the benefit of this risk reducing with increasing diversification is preserved.

\section{Conclusion}

Banks are increasingly diversifying their balance sheets across several assets in order to reduce their individual riskiness (Battiston et al. 2012; Wagner 2010). Accordingly, the true consequences of diversification particularly as it affects the stability of the financial system and the wider economy is actively being discussed by policy makers and academics (Battiston et al. 2012; Caccioli et al. 2014; Tasca et al. 2014; Wagner $2008,2010)$. We contribute to this discussion by studying the impact of diversification on systemic (i.e. likelihood of joint failures) and idiosyncratic risk (i.e. risk of a oneoff failure) using an agent based model that couples the financial system and the real economy. This approach not only leads to the emergence of a constantly evolving interbank and bank-firm network but also results in the emergence of shocks from the real sector that can be transmitted to the financial system via the evolving multi-layered network of bank-firm and bank-bank lending relationships.

Our findings suggest that diversification reduces idiosyncratic risk but increases systemic risk. We note that this finding leads to a higher cost for the society which ultimately results in a negative feedback on the real economy in terms of lower aggregate credit volume. Moreover, we find the emergence of a "robust yet fragile" behaviour from the model especially for low levels of diversification. This behaviour has been shown in several studies to characterise the financial system (Caccioli et al. 2014; Gai and Kapadia 2010) and simply implies that while the probability of a systemic crisis is low, the impact is however widespread (i.e. a large part of the financial system is affected) whenever it occurs. We then investigated the impact of introducing preferential attachment into the lending links of the bank-firm network and find that the risk profiles remain essentially the same as in the original model. However, we find that preferential attachment increases idiosyncratic risk but significantly reduces system risk in the financial system. 
We then investigated the effectiveness of a regulatory policy that permits diversification without exacerbating systemic risk but does not require banks to hold additional capital. The policy essentially promotes bank-firm credit transactions that result in the smallest increase in the similarity between banks in the financial system. We show that this policy is effective at reducing systemic risk. This is because the policy induces a self-arranging network topology between banks and firms that promotes dissimilarity in the financial system even with increasing diversification which ultimately reduces the build-up of systemic risk. Although, idiosyncratic risk is relatively higher with our policy however the benefit of this risk reducing with increasing diversification is preserved.

Our analysis side-steps the impact of correlation between sectors even though correlation can endogenously arise in the model particularly during periods of economic downturns. Nevertheless, it would be interesting to extend this work to explicitly characterise the stability of the financial system on the joint impact of diversification and correlation.

Acknowledgements This work was supported by the Nigerian Petroleum Trust Development Fund and the Quantitative \& Applied Spatial Economic Research Laboratory. We would like to thank Thomas Schroeder, Fabio Caccioli and J. Doyne Farmer for very helpful discussions and feedbacks at the initial stages of this project. OB appreciates Jadesola Onigbanjo for providing constructive evaluation of this paper.

Open Access This article is distributed under the terms of the Creative Commons Attribution 4.0 International License (http://creativecommons.org/licenses/by/4.0/), which permits unrestricted use, distribution, and reproduction in any medium, provided you give appropriate credit to the original author(s) and the source, provide a link to the Creative Commons license, and indicate if changes were made.

\section{Appendix A: model calibration and validation}

We initialise the model with parameters stipulated in Table 1 based on existing work in the literature (Gualdi et al. 2015; Klimek et al. 2015; Poledna and Thurner 2016). These works generally attempt to calibrate the model based on existing micro-founded behavioural studies as in Geanakoplos et al. (2012) and Hommes (2013). Gualdi et al. (2015) study the characteristics of the model in a space of parameters. They show for instance the existence of a phase transition from economic stability to instability that is robust to model modifications. Furthermore, Poledna and Thurner (2016) show that model can reproduce systemic risk profiles of the biggest banks in the Austrian financial system using the parameters in Table 1.

Consequently, the model is validated against its ability to reproduce an ensemble of stylized facts reported in real economies. In Fig. 12, we show the emergence of interesting macro and microeconomic phenomena from the decentralised model dynamics. Specifically, in Fig. 12, we observe the emergence of alternation of booms and recessions in aggregate output like business cycles reported in real national GDP data. These cycles have been found to endogenously arise when the assumptions of perfect ex ante coordination and walrasian market clearing are relaxed (Gualdi et al. 2015; Lengnick 2013).

The top right panel shows a negative correlation between change in output $(\Delta Y=$ $\left.Y_{t}-Y_{t+1}\right)$ and change in unemployment $\left(\Delta U=U_{t}-U_{t+1}\right)$ consistent with Okun's 
Table 1 Model simulation parameters

\begin{tabular}{lll}
\hline Parmeter & Description & Value \\
\hline $\begin{array}{ll}\text { Model parameters } \\
N_{h}\end{array}$ & Number of households & \\
$N_{f}$ & Number of firms & 800 \\
$N_{b}$ & Number of banks & 100 \\
$N_{s}$ & Number of sectors & 20 \\
$\phi_{s}$ & Bank diversification level & 20 \\
$\tau$ & Loan \& interest repayment & Variable \\
$\eta$ & Firm dividend & 0.05 \\
$r_{0}$ & Interest rate threshold & 0.25 \\
$\mu$ & Interest rate adjustment parameter & 0.05 \\
$M_{i b}$ & Number of banks approached on the interbank market & 0.01 \\
$M_{f}$ & Number of firms approached on the consumption market & 2 \\
$\alpha$ & Labour productivity & 2 \\
$C_{h}$ & Consumption budget & 0.02 \\
$\psi$ & Labour turnover probability & 0.8 \\
$\gamma_{y}$ & Production adjustment parameter & 0.05 \\
$\gamma_{p}$ & Price adjustment parameter & 0.1 \\
$z$ & Wage adjustment parameter & 0.1 \\
$\zeta$ & Reserve requirement & 0.001 \\
$\xi$ & Resolution overhead & 0.03 \\
\hline
\end{tabular}

law (Prachowny 1993). Beveridge's curve is shown to emerge from the model's labour dynamics in Fig. 12c i.e. a negative relationship between vacancy rate (measured as the ratio of job openings to the number of employable households) and unemployment rate (Nickell et al. 1960). Finally, we observe the emergence of a power law distribution of firm sizes in Fig. 12 consistent with empirical findings in real economies (Axtell 2001). Although, the agent based model we consider is simple, it still comes close to displaying phenomena observed in real economics emerging from the selforganising and complex interactions between the heterogeneous agents in an evolving system lacking central coordination without recourse to over-simplified assumptions of rationality, representative agents and general equilibrium. 


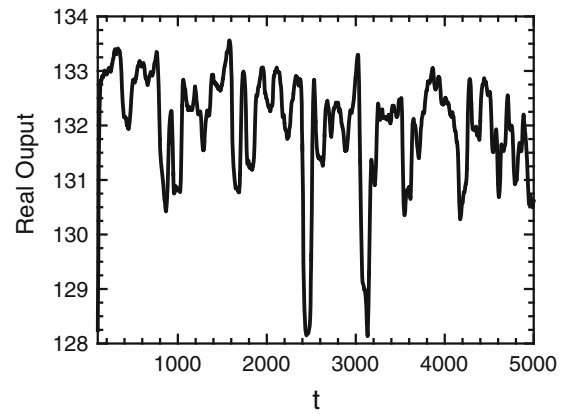

(a)

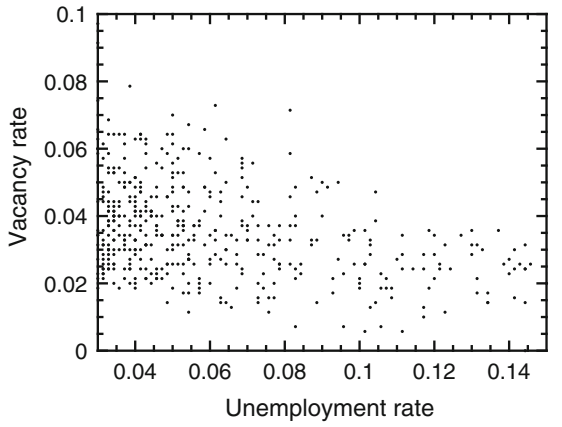

(c)

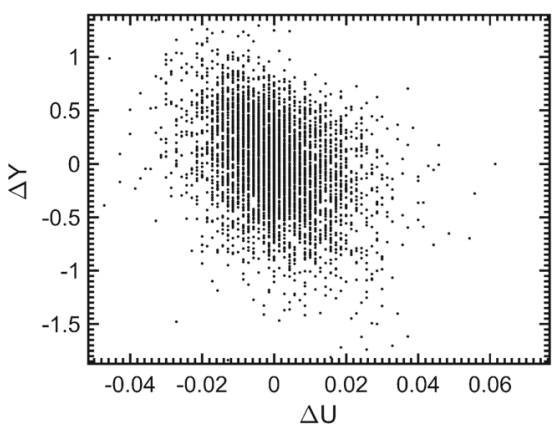

(b)

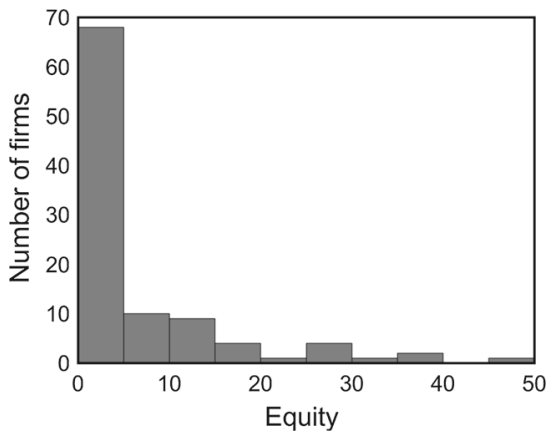

(d)

Fig. 12 Emergent macroeconomic phenomena from a representative simulation. a Output, b Okun's law, c Beveridge curve, d Power-law firm size distribution

\section{References}

Acharya VV (2009) A theory of systemic risk and design of prudential bank regulation. J Financ Stab 5(3):224-255

Acharya VV, Yorulmazer T (2005) Cash-in-the-market pricing and optimal bank bailout policy. SSRN Electron J. http://www.ssrn.com/abstract=685505

Acharya VV, Yorulmazer T (2007) Too many to fail—an analysis of time-inconsistency in bank closure policies. J Financ Intermed 16(1):1-31

Agarwal R, Ann Elston J (2001) Bank-firm relationships, financing and firm performance in Germany. Econ Lett 72:225-232

Albert R, Jeong H, Barabási A-L (2000) Error and attack tolerance of complex networks. Nature 406(6794):378-382

Albert R, Albert R, Barabási A-L (2002) Statistical mechanics of complex networks. Rev Mod Phys 74:47

Allen F, Carletti E (2006) Credit risk transfer and contagion. J Monet Econ 53(1):89-111

Allen F, Gale DM (2005) Systemic risk and regulation. SSRN Electron J. http://www.ssrn.com/abstract= 787797

Anand K, Gai P, Kapadia S, Brennan S, Willison M (2013) A network model of financial system resilience. J Econ Behav Organ 85:219-235

Axtell RL (2001) Zipf distribution of US firm sizes. Science 293(5536):1818-1820

Bartram SM, Brown GW, Hund JE (2007) Estimating systemic risk in the international financial system. J Financ Econ 86(3):835-869

Bask M (2012) Asset price misalignments and monetary policy. Int J Finance Econ 17(3):221-241

Battiston S, Gatti DD, Gallegati M, Greenwald B, Stiglitz JE (2012) Default cascades: when does risk diversification increase stability? J Financ Stab 8(3):138-149 
Benczur P, Cannas G, Cariboni J, Di Girolamo F, Maccaferri S, Petracco Giudici M (2017) Evaluating the effectiveness of the new EU bank regulatory framework: a farewell to bail-out? J Financ Stab 33:207-223

Bridges J, Gregory D, Nielsen M, Pezzini S, Radia A, Spaltro M (2014) The impact of capital requirements on bank lending. SSRN Electron J 486:1-35

Brooke M, Bush OPH, Edwards R, Ellis J, Francis W B, Harimohan R, Neiss K, Siegert C (2015) Measuring the macroeconomic costs and benefits of higher UK bank capital requirements. http://econpapers.repec. org/RePEc:boe:finsta:0035

Bullard JB, Neely CJ, Wheelock DC (2009) Systemic risk and the financial crisis: a primer. Review 91(Sep):403-418

Caccioli F, Catanach TA, Farmer JD (2011) Heterogeneity, correlations and financial contagion. Adv Complex Syst ACS 15:1250058. arXiv:1109.1213

Caccioli F, Shrestha M, Moore C, Farmer JD (2014) Stability analysis of financial contagion due to overlapping portfolios. J Bank Finance 46:233-245

Caccioli F, Farmer JD, Foti N, Rockmore D (2015) Overlapping portfolios, contagion, and financial stability. J Econ Dyn Control 51:50-63

Cai J, Saunders A, Steffen S (2012) Syndication, interconnectedness, and systemic risk. SSRN Electron J 34:105-120

Conlon T, Cotter J (2014) Anatomy of a bail-in. J Financ Stab 15:257-263

De Grauwe P, Macchiarelli C (2015) Animal spirits and credit cycles. J Econ Dyn Control 59:95-117

de Masi G, Gallegati M (2012) Bank-firms topology in Italy. Empir Econ 43(2):851-866

Delli Gatti D, Desiderio S, Gaffeo E, Cirillo P, Gallegati M (2011) Macroeconomics from the bottom-up. Volume 1 of new economic windows. Springer Milan, Milano

Dosi G, Fagiolo G, Roventini A (2010) Schumpeter meeting Keynes: a policy-friendly model of endogenous growth and business cycles. J Econ Dyn Control 34(9):1748-1767

Elsinger H, Lehar A, Summer M (2006) Risk assessment for banking systems. Manag Sci 52(9):1301-1314. https://doi.org/10.1287/mnsc.1060.0531

Erlingsson EJ, Cincotti S, Stefansson H, Sturluson JT, Teglio A, Raberto M (2014) Housing market bubbles and business cycles in an agent-based credit economy. Econ Open Access Open Assess E J 8:1-42

Fagiolo G, Roventini A (2012) Macroeconomic policy in DSGE and agent-based models. Revue de l'OFCE 124(5):67

Fay S (1997) The collapse of Barings. Norton, New York

Ferri G, Messori M (2000) Bank-firm relationships and allocative efficiency in Northeastern and Central Italy and in the South. J Bank Finance 24(6):1067-1095

Fidrmuc J, Schreiber P, Siddiqui M (2015) Information asymmetry, relationship banking and financing costs of SME's. SSRN Electron J. http://www.ssrn.com/abstract=2565350

Furfine C (2003) Interbank exposures: quantifying the risk of contagion. J Money Credit Bank 35(1):111128

Gaffeo E, Delli Gatti D, Desiderio S, Gallegati M (2008) Adaptive microfoundations for emergent macroeconomics. East Econ J 34(4):441-463

Gai P, Kapadia S (2010) Contagion in financial networks. Proc R Soc A Math Phys Eng Sci 466(2120):24012423

Gai P, Haldane A, Kapadia S (2011) Complexity, concentration and contagion. J Monet Econ 58(5):453-470

Geanakoplos J, Axtell R, Farmer JD, Howitt P, Conlee B, Goldstein J, Hendrey M, Palmer NM, Yang C-Y (2012) Getting at systemic risk via an agent-based model of the housing market. SSRN Electron J 102:53-58

Gualdi S, Tarzia M, Zamponi F, Bouchaud J-P (2015) Tipping points in macroeconomic agent-based models. J Econ Dyn Control 50:29-61

Hommes C (2013) Behavioral rationality and heterogeneous expectations in complex economic systems. Cambridge University Press, Cambridge

Hüser A C, Hałaj G, Kok C, Perales C, van der Kraaij A, (2017) The systemic implications of bail-in: A multi-layered network approach. J Financ Stab. https://www.sciencedirect.com/science/article/pii/ S1572308916302194

Klimek P, Poledna S, Doyne Farmer J, Thurner S (2015) To bail-out or to bail-in? Answers from an agentbased model. J Econ Dyn Control 50:144-154 
Lengnick M (2013) Agent-based macroeconomics: a baseline model. J Econ Behav Organ 86:102-120

Lengnick M, Wohltmann H-W (2016) Optimal monetary policy in a new Keynesian model with animal spirits and financial markets. J Econ Dyn Control 64:148-165

Liu Z (2015) Banking sector interconnectedness: what is it, how can we measure it and why does it matter? Tech. rep., Bank of England. http://www.bankofengland.co.uk/publications/Documents/ quarterlybulletin/2015/q2prerelease_1.pdf

Lux T (2016) A model of the topology of the bank-firm credit network andits role as channel of contagion. J Econ Dyn Control 66:36-53

Markowitz H (1952) Portfolio selection. J Finance 7(1):77-91

Marotta L, Miccichè S, Fujiwara Y, Iyetomi H, Aoyama H, Gallegati M, Mantegna RN (2015) Bank-firm credit network in Japan: an analysis of a bipartite network. PLoS ONE 10(5):e0123079

Martinez-Jaramillo S, Alexandrova-Kabadjova B, Bravo-Benitez B, Solórzano-Margain JP (2014) An empirical study of the Mexican banking system's network and its implications for systemic risk. J Econ Dyn Control 40:242-265

Merton RC (1974) On the pricing of corporate dept: the risk structure of interest rates. J Finance 29(2):23

Mistrulli PE (2011) Assessing financial contagion in the interbank market: maximum entropy versus observed interbank lending patterns. J Bank Finance 35(5):1114-1127

Montagna M, Kok C (2016) Multi-layered interbank model for assessing systemic risk. ECB Working Paper No. 1944. https://ssrn.com/abstract=2830546

Naimzada A, Pireddu M (2014) Dynamic behavior of product and stock markets with a varying degree of interaction. Econ Model 41:191-197

Nickell S, Nunziata L, Ochel W, Quintini G (1960) The Beveridge curve, unemployment and wages in the OECD from the 1960s to the 1990s. Change. http://www.nuffield.ox.ac.uk/users/nickell/papers/ TheBeveridgeCurve.pdf

Poledna S, Thurner S (2016) Elimination of systemic risk in financial networks by means of a systemic risk transaction tax. Quant Finance. https://doi.org/10.1080/14697688.2016.1156146

Poledna S, Molina-Borboa JL, Martinez-Jaramillo S, van der Leij M, Thurner S (2015) The multi-layer network nature of systemic risk and its implications for the costs of financial crises. J Financ Stab 20:70-81

Prachowny MFJ (1993) Okun's law: theoretical foundations and revised estimates. Rev Econ Stat 75(2):331336

Raffestin L (2014) Diversification and systemic risk. J Bank Finance 46:85-106

Tasca P, Mavrodiev P, Schweitzer F (2014) Quantifying the impact of leveraging and diversification on systemic risk. J Financ Stab 15:43-52

Tilman D (1999) The ecological consequences of changes in biodiversity: a search for general principles 101. Ecology 80(5):1455-1474

Wagner W (2008) The homogenization of the financial system and financial crises. J Financ Intermed 17(3):330-356

Wagner W (2010) Diversification at financial institutions and systemic crises. J Financ Intermed 19(3):373386

Wagner W (2011) Systemic liquidation risk and the diversity-diversification trade-off. J Finance 66(4):1141-1175

Wagner W, Marsh IW (2006) Credit risk transfer and financial sector stability. J Financ Stab 2(2):173-193

Westerhoff F (2012) Interactions between the real economy and the stock market: a simple agent-based approach. Discrete Dyn Nat Soc 2012:1-21 